\title{
Gastrointestinal symptoms and association with medication use patterns, adherence, treatment satisfaction, quality of life, and resource use in osteoporosis: baseline results of the MUSIC-OS study
}

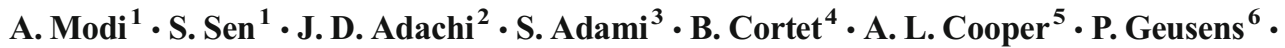 \\ D. Mellström ${ }^{7}$ - J. Weaver ${ }^{1}$ • J. P. van den Bergh ${ }^{6,8}$ - A. M. Nguyen ${ }^{1} \cdot$ S. Sajjan ${ }^{1}$ • \\ MUSIC-OS Study Group
}

Received: 29 June 2015 / Accepted: 25 October 2015 /Published online: 4 December 2015

(C) The Author(s) 2015. This article is published with open access at Springerlink.com

\begin{abstract}
Summary The Medication Use Patterns, Treatment Satisfaction, and Inadequate Control of Osteoporosis Study (MUSICOS) is a prospective, observational study of women with osteoporosis in Europe and Canada. At baseline, patients with gastrointestinal symptoms reported lower adherence to osteoporosis treatment, treatment satisfaction, and health-related quality of life, than those without gastrointestinal symptoms. Introduction The aim of the study was to examine gastrointestinal (GI) symptoms and the association between GI symptoms and treatment adherence, treatment satisfaction, and health-related quality of life (HRQoL) among osteoporotic women in Europe and Canada.

Methods Baseline results are reported here for a prospective study which enrolled postmenopausal, osteoporotic women

The members of the MUSIC-OS Study Group are listed in the appendix.

J. Weaver

jessica.weaver@merck.com

1 Merck and Co., Inc., Kenilworth, 2000 Galloping Hill Rd, Kenilworth, NJ 07033, USA

2 Division of Rheumatology, St. Joseph's Healthcare and McMaster University, Hamilton, ON, Canada

3 University of Verona, Verona, Italy

4 University Hospital of Lille, Lille Cedex, France

5 Bridge Medical Center, West Sussex, UK

6 Maastricht University Medical Center, Maastricht, The Netherlands

7 University of Gothenburg, Göteborg, Sweden

8 VieCuri Medical Center, Venlo, The Netherlands
\end{abstract}

who were initiating (new users) or continuing (experienced users) osteoporosis treatment at study entry (baseline). A patient survey was administered at baseline and included the occurrence of GI symptoms during 6-month pre-enrolment, treatment adherence (adherence evaluation of osteoporosis (ADEOS), score 0-22), treatment satisfaction (Osteoporosis Treatment Satisfaction Questionnaire for Medications (OPSAT-Q), score 0-100) and HRQoL (EuroQol-5 dimension (EQ-5D) utility, score 0-1; OPAQ-SV, score 0-100). The association between GI symptoms and ADEOS (experienced users), OPSAT-Q (experienced users), and HRQoL (new and experienced users) was assessed by general linear models adjusted for patient characteristics.

Results A total of 2959 patients (2275 experienced and 684 new users) were included. Overall, $68.1 \%$ of patients experienced GI symptoms in the past 6 months. Compared with patients without GI symptoms, patients with GI symptoms had lower mean baseline scores on most measures. The mean adjusted differences were ADEOS, -0.43; OPSAT-Q, -5.68; EQ-5D, -0.04 (new users) and -0.06 (experienced users), all $P<0.01$. GI symptoms were also associated with lower OPAQ-SV domain scores: physical function, -4.17 (experienced users); emotional status, -4.28 (new users) and -5.68 (experienced users); back pain, -5.82 (new users) and -11.33 (experienced users), all $P<0.01$.

Conclusions Patients with GI symptoms have lower treatment adherence and treatment satisfaction and worse HRQoL than patients without GI symptoms.

Keywords Bisphosphonates - Gastrointestinal ·

Health-related quality of life · Osteoporosis .

Postmenopausal $\cdot$ Treatment satisfaction 


\section{Introduction}

Osteoporosis-related fractures persist as a global health issue despite the availability of effective treatments to reduce fracture risk. In the European Union, osteoporosis affects an estimated 22 million women and 5.5 million men, resulting in 3.5 million new fragility fractures annually and 37 billion euros per year in direct health care costs [1]. In Canada, there were 57,413 acute care admissions, 832,594 hospitalized days, and $\$ 1.2$ billion in acute care costs attributable to osteoporosis fractures during 20072008 [2]. Patients who sustain fragility fractures experience significantly worse health-related quality of life (HRQoL) $[3-5]$ and face an increased risk of mortality $[6,7]$.

There are several treatment options with demonstrated efficacy in reducing fracture risk in osteoporotic patients, including bisphosphonates. Bisphosphonates are the most commonly prescribed therapy. However, among patients who initiate treatment, adherence to and persistence with therapy is often poor in clinical practice. Among patients initiating bisphosphonate therapy, only approximately $40-60 \%$ are adherent to therapy during the first year [8-10] and a similar proportion are non-persistent in their first year of treatment [10-12]. The consequences of low adherence and persistence include greater fracture risk $[10,13]$ and the sequalae of higher health care utilization and costs [14-16].

Gastrointestinal (GI) symptoms among patients on oral bisphosphonates may also contribute to worse clinical outcomes. Although controlled trials have found no differences in the rate of GI symptoms among patients (with and without pre-existing GI disorders) treated with oral bisphosphonates compared with placebo [17, 18], analyses of real-world data have noted upper GI complaints often manifesting as dyspepsia, gastroesophageal reflux, and nausea [19] and less frequently as esophagitis [20] and gastric ulcers [21]. Patients with a history of GI disorders are more likely to develop symptoms on oral bisphosphonate treatment [22-24], and both pre-treatment gastrointestinal complaints and complaints while on treatment have been associated with discontinuation of oral bisphosphonates and other osteoporosis therapies [22, 25-27]. Additionally, evidence from the POSSIBLE-US observational study of osteopenic and osteoporotic women suggests that patients who experience GI symptoms on treatment have lower treatment satisfaction than patients without GI complaints [26] and lower treatment satisfaction was associated with a higher risk of treatment discontinuation or switching [28]. GI complaints on treatment were also linked to lower HRQoL among patients newly initiating therapy [26]. However, the rate of GI symptoms and the relationship between GI symptoms and patient-reported outcomes has not been well explored in osteoporotic women in the EU and Canada.
This study focuses on postmenopausal women in the EU and Canada who were initiating or continuing oral pharmacological therapy for osteoporosis at the start of the study. The objectives were to identify treatment patterns, GI symptoms, and the association between GI symptoms and treatment adherence, treatment satisfaction, healthrelated quality of life, and health care resource utilization.

\section{Methods}

\section{Study design and participants}

The study design, recruitment, and patient baseline characteristics of the Medication Use Patterns, Treatment Satisfaction, and Inadequate Control of Osteoporosis Study (MUSIC-OS) have been previously reported [29]. In brief, MUSIC-OS investigators enrolled postmenopausal women aged 55 and older, with a physician diagnosis of osteoporosis, from 96 primary care and specialty clinics in Canada, France, Italy, the Netherlands, Sweden, and the UK. The study was carried out in accordance with the Declaration of Helsinki, the standards of good clinical practice, and either the local ethics boards of the participating institutions or a central institutional review board. All participants provided written informed consent prior to study enrolment. Potential enrollees were identified at each site at the time of a medical consultation. This analysis describes the results of data collected at the enrollment (baseline) visit for new users who were initiating oral pharmacological treatment for osteoporosis and experienced users who were continuing the same oral pharmacological treatment.

Qualifying oral pharmacologic treatment for osteoporosis in MUSIC-OS included bisphosphonates (e.g., alendronate, risedronate, ibandronate), calcitonin, strontium ranelate, and selective estrogen receptor modulators (SERMs [e.g., raloxifene, and bazedoxifene]). Calcium, vitamin $\mathrm{D}$, and estrogen and other hormone replacement therapy were not considered pharmacologic treatments for osteoporosis in this study. New users were patients either initiating qualifying oral pharmacological therapy at enrollment or receiving qualifying oral pharmacological therapy for less than 3 months prior to enrollment with no previous history of any osteoporosis pharmacological therapy. Experienced users were receiving the same qualifying oral pharmacological therapy for at least 3 months continuously prior to enrollment and were continuing treatment at the time of enrollment. Each cohort was further categorized by the presence or absence of GI symptoms by asking patients at baseline if they had experienced any GI symptoms in the 6 months prior to enrollment. 


\section{Measures}

Patients were interviewed, and their medical chart history was reviewed during the enrolment visit (i.e., baseline visit) to obtain information on qualifying oral pharmacological osteoporosis therapy (defined above), concomitant medications, and GI symptoms. Concomitant medications included other medications/supplements taken for osteoporosis (e.g., calcium and/or vitamin D, estrogen and hormone replacement therapy, parathyroid hormone), gastrointestinal conditions (e.g., antacids), and drugs linked to gastrointestinal conditions, e.g., acetaminophen, non-steroidal anti-inflammatory drugs). The presence and type of GI symptoms were assessed by asking the patient if she had experienced any of a defined list of upper (heartburn/acid reflux, upset stomach/indigestion, nausea/ vomiting, pain behind breastbone, pain or difficulty swallowing, stomach pain above navel) or lower (diarrhea or constipation, stomach pain below navel, bloating) GI problems in the last 6 months. Health care utilization in the 3 months prior to enrolment was assessed by asking patients to report medical services utilized specific to osteoporosisrelated concerns and those specific to gastrointestinal-related concerns. Service categories captured were visits to family physician/general practitioner and specialists.

Patients completed four instruments to assess treatment adherence, treatment satisfaction, and HRQoL. Adherence was assessed among experienced users with the 12-item adherence evaluation of osteoporosis (ADEOS) treatment questionnaire, which has been validated in women with osteoporosis [30]. Scores range from 0 to 22 with scores $\geq 20$ predicative of a high probability of medication persistence. Treatment satisfaction was measured with the Osteoporosis Treatment Satisfaction Questionnaire for Medications (OPSAT-Q), which uses Likert scales to assess four domains (treatment convenience, confidence in daily functioning, overall satisfaction with treatment, and side effects) with the total score reported on a $0-100$ scale (higher scores indicating greater satisfaction) [31]. The OPSAT-Q has been validated in women taking bisphosphonates [31]. HRQoL was evaluated with the EuroQol-5 dimension (EQ-5D) utility which assesses health state [32], and the disease-specific Osteoporosis Assessment Questionnaire-Short Version (OPAQ-SV) which assesses health status in three domains: physical function, emotional status, and back pain [33].

\section{Statistical analyses}

The recruitment goal was 3300 treated patients to achieve a sample size of 2640 , assuming $20 \%$ loss to follow-up. This sample size is estimated assuming a normal distribution to provide $95 \%$ confidence intervals at a 0.05 significance level. We computed descriptive statistics for GI symptoms. The difference in the proportion of new and experienced users reporting GI symptoms was examined by chi-squared test. The association between the presence/absence of GI symptoms and ADEOS, OPSAT-Q, EQ-5D, and OPAQ-SV scores was assessed with general linear models. Odd ratios for GI- and OP-related health care utilization were computed by logistic regression models. Separate models were constructed for each cohort (experienced vs. new user) and each measure (ADEOS, OPSAT-Q, EQ-5D, OPAQ$\mathrm{SV}$ ) and each component (general practitioner or specialist visit) of GI- and OP-related health care utilization. Modeling was conducted in two phases: an initial full model followed by a final reduced model. The initial full models were adjusted for the following patient characteristics: age group in years (50-59 [reference]; 60-69, 70-79; $\geq 80)$, race (white [reference], non-white), BMI category (underweight $<18.5$; normal 18.50-24.99 [reference]; overweight 25.0025.99 ; obese $\geq 30$ ), duration of osteoporosis at study entry in years $(<1$ [reference]; $1-<5,5-10 ;>10)$, duration of pharmacological treatment for osteoporosis at study entry in years $(<1$ [reference]; $1-<5,5-10 ;>10$; this variable was excluded from the model for new users), history of falls in the past 12 months (yes, no [reference]), history of osteoporotic fracture at any time in the past (yes, no [reference]), presence of any selected comorbid conditions (yes, no [reference]; conditions included hypertension, diabetes, chronic kidney disease, rheumatoid arthritis, hypothyroidism, anorexia nervosa, celiac disease, inflammatory bowel disease, lactose intolerance, lupus, asthma, stroke, dementia, chronic obstructive pulmonary disease), combination treatment (receiving bisphosphonates and nonbisphosphonates, receiving bisphosphonates [reference]), treatment class (receiving non-bisphosphonates, receiving bisphosphonates [reference]), and concomitant medication use (yes, no [reference]). Because not all participants had values for each covariate (e.g., race information was missing in France), the final model was a reduced model selected by using the subset of covariates in the full model that was significant at $P \leq 0.15$ by backward elimination. The ADEOS and OPSAT-Q scores were not modeled for new users because these patients were either initiating osteoporosis therapy at study entry or had $<3$ months exposure to therapy. Covariates with unstable confidence intervals were excluded from models.

\section{Results}

\section{Enrollment}

We enrolled 3335 patients from 96 sites. The number of patients ( $\%$ of total study enrollment) and number of sites by country, respectively were UK, 873 patients $(26.2 \%), 22$ sites; Canada, 760 patients (22.8 \%), 15 sites; France, 661 patients (19.8\%), 27 sites; Italy, 593 patients (17.8\%), 22 sites; 
Netherlands, 225 patients $(6.7 \%), 7$ sites; Sweden, 223 $(6.7 \%), 3$ sites. Of the 3335 enrolled patients, 2980 were protocol eligible, treated patients. After excluding 21 patients with missing data for GI symptoms, there were 2275 patients in the experienced user cohort and 684 patients in the new user cohort.

\section{Treatment patterns}

Bisphosphonates were the most common treatment overall (79.9 \%) and among each user cohort and GI symptom group (Table 1). Among new users, $44.8 \%$ were not receiving pharmacological osteoporosis therapy at the baseline visit. Although inclusion in this analysis required that all patients be treated with qualifying osteoporosis medications, the percentage of new users on pharmacological therapy at enrollment is less than 100 because some new users were prescribed their treatment on the day of the enrollment visit. Overall, $10.2 \%$ of patients were taking only non-pharmacological oral medications (calcium and/or vitamin D treatment, estrogen, and/or hormone replacement therapy), and the majority of these patients were new users. Among all patients, $71.8 \%$ reported taking a calcium and/or vitamin D supplement (data not shown). Experienced users had been taking oral pharmacologic therapy for approximately 4 years.

\section{Frequency of gastrointestinal symptoms}

There were 2015 (68.1\%) patients who reported GI symptoms in the 6 months prior to enrollment (Table 2). The proportion of experienced users reporting GI symptoms was higher than new users $(69.1$ vs. $64.6 \% ; P<0.03)$. The most common upper GI symptoms reported by all patients were heartburn/acid reflux (35.0 \%) followed by upset stomach/ indigestion $(28.4 \%)$. Diarrhea or constipation (38.2\%) and bloating (37.3\%) were the most frequently reported lower GI symptoms.

\section{Adherence and treatment satisfaction}

Among experienced users ( $n=2228), 49.2 \%$ had an ADEOS score $\geq 20$, indicative of a high probability of medication

Table 1 Osteoporosis treatment patterns at enrolment

\begin{tabular}{|c|c|c|c|c|c|c|c|c|c|}
\hline \multirow[b]{2}{*}{ Characteristic } & \multicolumn{3}{|l|}{ New users } & \multicolumn{3}{|c|}{ Experienced users } & \multicolumn{3}{|l|}{ All users } \\
\hline & $\begin{array}{l}\text { GI } \\
\text { Symptoms } \\
(\mathrm{n}=442)\end{array}$ & $\begin{array}{l}\text { No GI } \\
\text { Symptoms } \\
(\mathrm{n}=242)\end{array}$ & $\begin{array}{l}\text { All } \\
(\mathrm{n}=684)\end{array}$ & $\begin{array}{l}\text { GI } \\
\text { Symptoms } \\
(n=1,573)\end{array}$ & $\begin{array}{l}\text { No GI } \\
\text { Symptoms } \\
(\mathrm{n}=702)\end{array}$ & $\begin{array}{l}\text { All } \\
(n=2,275)\end{array}$ & $\begin{array}{l}\text { GI } \\
\text { Symptoms } \\
(\mathrm{n}=2015)\end{array}$ & $\begin{array}{l}\text { No GI } \\
\text { Symptoms } \\
(\mathrm{n}=944)\end{array}$ & $\begin{array}{l}\text { All } \\
(n=2,959)\end{array}$ \\
\hline \multicolumn{10}{|l|}{ Osteoporosis medication } \\
\hline Bisphosphonates, $n(\%)$ & $\begin{array}{l}223 \\
(50.5)\end{array}$ & $\begin{array}{l}131 \\
(54.1)\end{array}$ & $\begin{array}{l}354 \\
\quad(51.8)\end{array}$ & $\begin{array}{l}1372 \\
(87.2)\end{array}$ & $\begin{array}{l}606 \\
\quad(86.3)\end{array}$ & $\begin{array}{l}1978 \\
(86.9)\end{array}$ & $\begin{array}{l}1595 \\
(79.2)\end{array}$ & $737(78.1)$ & $\begin{array}{l}2378 \\
\quad(79.9)\end{array}$ \\
\hline Non-bisphosphonates, $n(\%)$ & $23(5.2)$ & $7(2.9)$ & $30(4.4)$ & $209(13.3)$ & $108(15.4)$ & $\begin{array}{l}317 \\
(13.9)\end{array}$ & $232(11.5)$ & $115(12.2)$ & $\begin{array}{l}347 \\
(11.7)\end{array}$ \\
\hline $\begin{array}{l}\text { Bisphosphonates and non- } \\
\text { bisphosphonates, } n(\%)\end{array}$ & $2(0.5)$ & $0(0.0)$ & $2(0.3)$ & $9(0.6)$ & $12(1.7)$ & $21(0.9)$ & $11(0.5)$ & $12(1.3)$ & $23(0.8)$ \\
\hline $\begin{array}{l}\text { Not receiving qualifying oral } \\
\text { pharmacological osteoporosis } \\
\text { medication }^{\mathrm{a}}, n(\%)\end{array}$ & $198(44.8)$ & $104(43.0)$ & $302(44.2)$ & $1(0.1)$ & $0(0.0)$ & $1(0.0)^{\mathrm{b}}$ & $199(9.9)$ & $104(11.0)$ & $303(10.2)$ \\
\hline \multicolumn{10}{|l|}{$\begin{array}{l}\text { Duration of qualifying oral, } \\
\text { pharmacological osteoporosis } \\
\text { medication at enrolment, months }\end{array}$} \\
\hline Any therapy, mean (SD) & $0.3(0.61)$ & $0.2(0.57)$ & $\begin{array}{l}0.3 \\
(0.60)\end{array}$ & $\begin{array}{l}48.8 \\
\quad(39.11)\end{array}$ & $\begin{array}{l}46.1 \\
\quad(36.92)\end{array}$ & $\begin{array}{l}48.0 \\
\quad(38.46)\end{array}$ & $\begin{array}{l}42.3 \\
\quad(39.98)\end{array}$ & $\begin{array}{l}38.6 \\
\quad(37.79)\end{array}$ & $\begin{array}{l}41.1 \\
\quad(39.33)\end{array}$ \\
\hline Bisphosphonates, mean (SD) & $0.3(0.60)$ & $0.2(0.56)$ & $\begin{array}{l}0.2 \\
(0.58)\end{array}$ & $\begin{array}{l}48.0 \\
\quad(38.19)\end{array}$ & $\begin{array}{l}43.8 \\
\quad(35.51)\end{array}$ & $\begin{array}{l}46.7 \\
\quad(37.43)\end{array}$ & $\begin{array}{l}41.3 \\
\quad(39.10)\end{array}$ & $\begin{array}{l}36.1 \\
\quad(36.27)\end{array}$ & $\begin{array}{l}39.7 \\
\quad(38.30)\end{array}$ \\
\hline Non-bisphosphonates, mean (SD) & $\begin{array}{l}0.4 \\
\quad(0.72)\end{array}$ & $\begin{array}{l}0.4 \\
\quad(0.79)\end{array}$ & $\begin{array}{l}0.4 \\
\quad(0.72)\end{array}$ & $\begin{array}{l}51.5 \\
\quad(43.71)\end{array}$ & $\begin{array}{l}55.0 \\
\quad(44.91)\end{array}$ & $\begin{array}{l}52.7 \\
\quad(44.09)\end{array}$ & $\begin{array}{l}46.5 \\
\quad(44.22)\end{array}$ & $\begin{array}{l}51.7 \\
\quad(45.44)\end{array}$ & $\begin{array}{l}48.2 \\
\quad(44.63)\end{array}$ \\
\hline
\end{tabular}

${ }^{a}$ Some new users had not started qualifying oral pharmacological osteoporosis medication (bisphosphonates [e.g., alendronate, risedronate, ibandronate)], calcitonin, strontium, and SERM [raloxifene], and bazedoxifene) at the enrolment visit because they received their prescription on the day of the enrolment visit. Calcium and/or vitamin D treatment and estrogen and/or hormone replacement therapy were not considered relevant osteoporosis treatment

${ }^{\mathrm{b}}$ One patient classified as an experienced user was reported as not having received qualifying oral pharmacological osteoporosis medication. This patient was removed from the analysis of the association between gastrointestinal symptoms and patient-reported outcomes

GI gastrointestinal 
Table 2 Patient-reported gastrointestinal symptoms during 6 months prior to enrollment

\begin{tabular}{|c|c|c|c|c|c|c|}
\hline & \multicolumn{2}{|l|}{ New users } & \multicolumn{2}{|c|}{ Experienced users } & \multicolumn{2}{|l|}{ All users } \\
\hline & $\begin{array}{l}\text { GI symptoms } \\
(n=442)\end{array}$ & $\begin{array}{l}\text { All } \\
(n=684)\end{array}$ & $\begin{array}{l}\text { GI symptoms } \\
(n=1573)\end{array}$ & $\begin{array}{l}\text { All symptoms } \\
(n=2275)\end{array}$ & $\begin{array}{l}\text { GI symptoms } \\
(n=2015)\end{array}$ & $\begin{array}{l}\text { All } \\
(n=2959)\end{array}$ \\
\hline & $n(\%)$ & $\%$ & $n(\%)$ & $\%$ & $n(\%)$ & $\%$ \\
\hline $\begin{array}{l}\text { Any GI problems in the past } \\
6 \text { months }\end{array}$ & $442(100)$ & 64.6 & $1573(100)$ & 69.1 & $2015(100)$ & 68.1 \\
\hline Any upper GI & $341(77.1)$ & 49.9 & $1232(78.3)$ & 54.2 & $1573(78.1)$ & 53.2 \\
\hline Heartburn/acid reflux & $210(47.5)$ & 30.7 & $826(52.5)$ & 36.3 & $1036(51.4)$ & 35.0 \\
\hline Upset stomach/indigestion & $179(40.5)$ & 26.2 & $661(42.0)$ & 29.1 & $840(41.7)$ & 28.4 \\
\hline Nausea/vomiting & $76(17.2)$ & 11.1 & $318(20.2)$ & 14.0 & $394(19.6)$ & 13.3 \\
\hline Pain behind breastbone & $111(25.1)$ & 16.2 & $339(21.6)$ & 14.9 & $450(22.3)$ & 15.2 \\
\hline Pain or difficulty swallowing & $45(10.2)$ & 6.6 & $233(14.8)$ & 10.2 & $278(13.8)$ & 9.4 \\
\hline Stomach pain above navel & $94(21.3)$ & 13.7 & $318(20.2)$ & 14.0 & $412(20.4)$ & 13.9 \\
\hline Any lower GI & $344(77.8)$ & 50.3 & $1261(80.2)$ & 55.4 & $1605(79.7)$ & 54.2 \\
\hline Diarrhea or constipation & $226(51.1)$ & 33.0 & $904(57.5)$ & 39.7 & $1130(56.1)$ & 38.2 \\
\hline Stomach pain below navel & $87(19.7)$ & 12.7 & $349(22.2)$ & 15.3 & $436(21.6)$ & 14.7 \\
\hline Bloating & $238(53.8)$ & 34.8 & $867(55.1)$ & 38.1 & $1105(4.8)$ & 37.3 \\
\hline
\end{tabular}

GI gastrointestinal

persistence (data not shown). ADEOS scores $\geq 20$ were less frequent among experienced users with GI symptoms compared with users without GI symptoms (45.5 vs. $57.6 \%$; data not shown). The association between GI symptoms and ADEOS and OPSAT-Q scores, adjusted for patient demographic and clinical characteristics, is shown in Table 3. The adjusted mean difference between the GI and no GI symptom groups was $-0.43(P<0.001)$ with lower mean ADEOS scores in the GI symptom group. Treatment satisfaction measured by OPSAT-Q score was also significantly lower among experienced users with GI symptoms: The mean adjusted difference between the GI and no GI symptom groups was $-5.68(P<0.0001)$.

\section{Health-related quality of life}

The association between GI symptoms and measures of HRQoL, adjusted for patient characteristics, is shown in
Table 4. Compared with patients without GI symptoms, patients with GI symptoms had significantly lower mean adjusted EQ-5D utility scores in both the new user (mean difference $-0.04, P<0.0099$ ) and experienced user (mean difference $-0.06, P<0.0001)$ cohorts. For the diseasespecific OPAQ-SV, GI symptoms in new users were associated with significantly lower adjusted mean scores in the domains of emotional status (mean difference -4.28 , $P<0.01$ ) and back pain (mean difference -5.82 , $P<0.01$ ). Experienced users with GI symptoms had lower scores in all three domains with adjusted mean differences of -4.17 for physical function, -5.68 for emotional status, and -11.33 for back pain (all $P<0.0001$ ).

\section{Health care resource utilization}

The likelihood of osteoporosis-related and GI-related health care utilization among patients with GI symptoms

Table 3 Multivariate analyses of the association between GI symptoms and treatment adherence (ADEOS) and treatment satisfaction (OPSAT-Q) scores for experienced users

\begin{tabular}{|c|c|c|c|c|c|}
\hline & $n$ & GI symptoms ${ }^{\mathrm{a}}$ & No GI symptoms ${ }^{\mathrm{a}}$ & Difference $^{\mathrm{a}}(95 \% \mathrm{CI})$ & $P$ value \\
\hline ADEOS score (experienced users) ${ }^{b}$ & 2225 & 19.02 & 19.45 & $-0.43(-0.672,-0.182)$ & 0.0007 \\
\hline OPSAT-Q score (experienced users) ${ }^{\mathrm{c}}$ & 2212 & 77.94 & 83.62 & $-5.68(-7.017,-4.335)$ & $<0.0001$ \\
\hline
\end{tabular}

${ }^{\mathrm{a}}$ Values are adjusted means from the generalized linear model with backward elimination

${ }^{\mathrm{b}}$ Scored 0-22 with higher scores indicating greater adherence to treatment. Adjustment variables retained in the model were body mass index, duration of osteoporosis, and treatment class

${ }^{\mathrm{c}}$ Scored $0-100$ with higher scores indicating greater treatment satisfaction. Adjustment variables retained in the model were age, body mass index, history of falls, treatment class, and concomitant medication use

GI gastrointestinal 
Table 4 Association between GI symptoms and measures of health-related quality of life for new and experienced users

\begin{tabular}{llllll}
\hline \multicolumn{7}{c}{$n$} & GI symptoms $^{\mathrm{a}}$ & No GI symptoms $^{\mathrm{a}}$ & Difference $^{\mathrm{a}}(95 \% \mathrm{CI})$ & $P$ value \\
\hline EQ-5D utility score & & & & & \\
New users & 678 & 0.74 & 0.78 & $-0.04(-0.064,-0.009)$ & 0.0099 \\
Experienced users & 2258 & 0.75 & 0.81 & $-0.06(-0.071,-0.041)$ & $<0.0001$ \\
OPAQ-SV physical function score & & & & \\
New users & 675 & 69.23 & 70.42 & $-1.18(-4.105,1.743)$ & 0.4279 \\
Experienced users & 2267 & 71.93 & 76.10 & $-4.17(-5.812,-2.536)$ & $<0.0001$ \\
OPAQ-SV emotional status score & & & $-4.28(-7.292,-1.278)$ & 0.0053 \\
New users & 675 & 58.62 & 62.90 & $-5.68(-7.560,-3.798)$ & $<0.0001$ \\
Experienced users & 1788 & 57.46 & 63.14 & & \\
OPAQ-SV back pain score & & & $-5.82(-10.200,-1.439)$ & 0.0093 \\
New users & 674 & 52.19 & 58.01 & $-11.33(-13.717,-8.945)$ & $<0.0001$ \\
Experienced users & 2269 & 53.54 & 64.87 &
\end{tabular}

${ }^{a}$ Values are adjusted means from the generalized linear model with backward elimination

${ }^{\mathrm{b}}$ Scored $0-1 ; 0=$ worst imaginable health, $1=$ best imaginable health. Adjustment variables retained in the model for new users were age, body mass index, duration of osteoporosis, history of fractures, history of falls, and concomitant medication use. Adjustment variables retained in the model for experienced users were age, body mass index, duration of osteoporosis, history of fractures, history of falls, comorbidities, treatment class, and concomitant medication use

${ }^{\mathrm{c}}$ Scored 0-100 with higher scores indicating better health status. Adjustment variables retained in the model for new users were age, body mass index, history of fractures, history of falls, treatment class, and concomitant medication use. Adjustment variables retained in the model for experienced users were age, body mass index, duration of osteoporosis, duration of osteoporosis treatment, history of fractures, history of falls, treatment class and concomitant medication use

${ }^{\mathrm{d}}$ Scored 0-100 with higher scores indicating better health status. Adjustment variables retained in the model for new users were age, body mass index, history of fractures, and treatment class. Adjustment variables retained in the model for experienced users were age, race, body mass index, duration of osteoporosis, duration of osteoporosis treatment, history of fractures, history of falls, treatment class, comorbidities, and concomitant medication use

${ }^{\mathrm{e}}$ Scored 0-100 with higher scores indicating better health status. Adjustment variables retained in the model for new users were body mass index, treatment class, and concomitant medication use. Adjustment variables retained in the model for experienced users were age, body mass index, duration of osteoporosis treatment, history of fractures, history of falls, treatment class, and concomitant medication use

GI gastrointestinal (reference: no GI symptoms), adjusted for patient characteristics, is shown in Fig. 1. Among new users with GI symptoms, there was a non-significant trend for higher odds of visiting general practitioners and specialists for osteoporosis-related services compared with new users without GI symptoms. However, experienced users with GI symptoms had a significantly higher risk of osteoporosis-related service utilization for general practitioner visits (odds ratio [OR]: $1.35,95 \% \mathrm{CI}=1.05-1.73$, $P<0.03$ ) but not specialist visits. The most pronounced difference between experienced users with and without GI symptoms was in GI-related service utilization. Experienced users with GI symptoms had approximately ninefold higher risk (95\% CI=4.58-17.86, $P<0.0001)$ for GIrelated general practitioner visits and 4.2 higher odds (95 \% CI $=1.79-9.93, P=0.001$ ) of GI-related specialist visits compared with experienced users with no GI symptoms.

\section{Discussion}

The results of this baseline analysis of treated patients in MUSIC-OS reveal the high rate of GI symptoms in this cohort and the negative association of GI symptoms with patientreported outcomes. The presence of GI symptoms was associated with small but consistently negative decrements in medication adherence, treatment satisfaction, and HRQoL.

At baseline, $68.1 \%$ of patients reported GI symptoms in the last 6 months which is higher than observed in either POSSIBLE-EU [34] or POSSIBLE-US [26]. This is likely a result of methodological differences in capturing GI disorders. In the POSSIBLE-EU study, $22 \%$ of patients had current or prior upper GI disorders and $9 \%$ had current or prior lower GI disorders [34]. However, POSSIBLE-EU employed a narrower list of specific upper (GERD reflux, dyspepsia) and lower GI (irritable bowel syndrome, Crohn's disease) disorders than MUSIC-OS, and site investigators (not patients) 


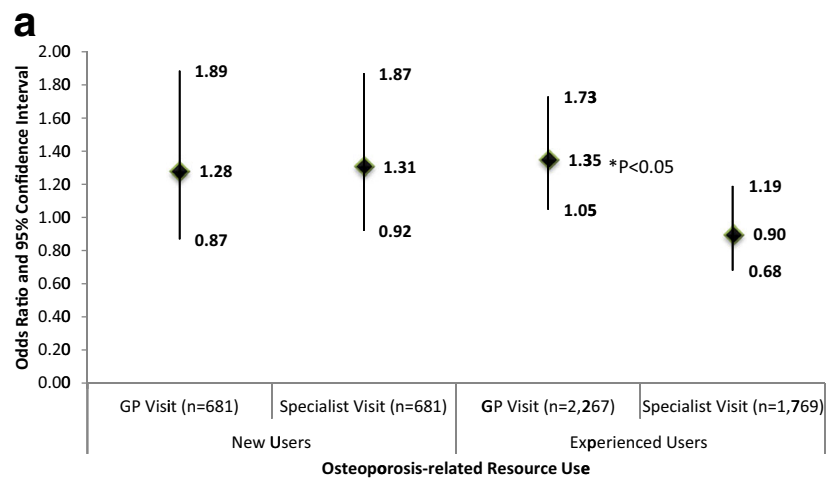

Fig. 1 a Likelihood of osteoporosis-related health care resource use for new and experienced users with and without GI symptoms. Values are adjusted odds ratios from the logistic regression model with backward elimination. Adjustment variables retained in the model for GP visits were as follows: among new users: treatment class and concomitant medication use; among experienced users: duration of osteoporosis, history of fractures, comorbidities, and treatment class. Adjustment variables retained in the model for specialist visits were as follows: among new users: treatment class, concomitant medication use, and comorbidities; among experienced users: age, race, duration of osteoporosis, history of fractures, and treatment class: $G I$

reported GI disorders which may have limited reporting to those GI disorders that resulted in medical consultation or treatment. In the POSSIBLE-US study, $21 \%$ of patients reported a constellation of upper and lower GI symptom similar to those defined in the MUSIC-OS protocol [26]. However, our results are based on a 6-month recall period, and POSSIBLE-US symptoms were captured "at study entry." The recall period is a likely contributor to the difference in rate of GI symptoms between the two studies. For example, $31 \%$ of POSSIBLE-US participants had a history of gastroesophageal reflux disease, a subset of upper GI symptoms, which is higher than the rate $(21 \%)$ reported for all upper and lower GI symptoms at study entry. The proportion of patients using GI medications was similar among the two studies: $20.7 \%$ of MUSIC-OS patients used GI medications in the last 12 months compared with approximately $25 \%$ of POSSIBLE-US participants at study entry, suggesting a similar rate of GI conditions treated with medications although the difference in recall period (last 12 months vs. study entry) precludes a direct comparison. Irrespective of methodological differences, the results of POSSIBLE-US and MUSIC-OS suggest that GI complaints are quite common among women initiating or continuing osteoporosis therapy.

Among all experienced users (with and without GI symptoms), only $49.2 \%$ had an ADEOS score $\geq 20$, which is indicative of a high probability of medication persistence. Although ADEOS scores were not well correlated with adherence as measured by medication possession ratio (MPR) in the validation study [30], our results are within the range of adherence to osteoporosis therapy observed in administrative claims studies that calculated adherence as MPR. An MPR

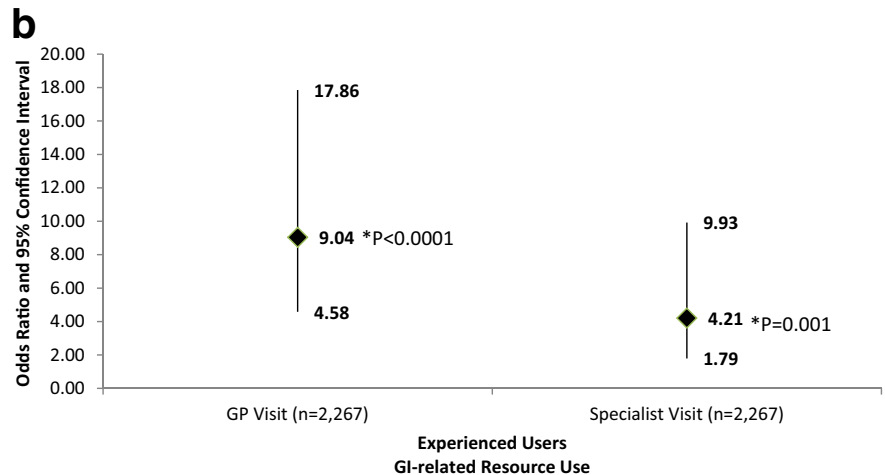

gastrointestinal, $G P$ general practitioner. b Likelihood of gastrointestinal-related health care resource use for experienced users with and without GI symptoms. Values are adjusted odds ratios from the logistic regression model with backward elimination. Adjustment variables retained in the model for GP visits were as follows: age group, duration of osteoporosis, history of fractures, history of falls, treatment class, and concomitant medication use. Adjustment variables retained in the model for specialist visits were body mass index, duration of osteoporosis treatment, history of fractures, and concomitant medication use. GI gastrointestinal, GP general practitioner

threshold of 0.80 is commonly used to distinguish between adherence and non-adherence; in the first year of therapy, typically $34-55 \%$ of patients are adherent to pharmacological osteoporosis treatments [8-10]. GI symptoms were associated with a small but significant decrease in ADEOS scores. The association between GI symptoms and lower ADEOS scores is consistent with previous studies of osteoporosis medication persistence during follow-up. In POSSIBLE-US, women with GI symptoms at study entry were $38 \%$ more likely to discontinue therapy within 6 months [26]. A higher risk of osteoporosis therapy discontinuation has been observed among patients taking GI medication [35, 36]. MUSIC-OS patients are being followed for 12 months, and future analysis will explore the relationship between recurrent GI symptoms, therapy discontinuation, and adherence as measured by ADEOS scores.

GI symptoms were also associated with consistently lower treatment satisfaction and HRQoL scores. In US studies, decrements in treatment satisfaction have been linked with increasing severity of side effects [28] and with the presence of GI side effects in particular [26]. Women treated with bisphosphonates were more likely to report GI side effects than women treated with other osteoporosis therapies [26], and upper GI symptoms during bisphosphonate therapy are a prominent risk factor for early treatment discontinuation [27]. The lower HRQoL scores we observed in patients with GI symptoms are also consistent with POSSIBLE-US results: Among new users, GI side effects at 6 months were associated with lower mean OPAQ-SV emotional status at 6 months [26] and lower OPAQ-SV physical function at study entry predicted non-persistence with initial therapy [37]. Our results coupled 
with previous studies suggest that the selection of pharmacologic treatment for osteoporotic women should account for preexisting GI symptoms and the potential for posttreatment GI symptoms to minimize the risk of therapy discontinuation.

MUSIC-OS is an observational study, and there are inherent limitations. In order to ensure robust implementation of the protocol, we screened sites based on their experience and ability to conduct observational research which may have biased the sample to physicians who are more engaged in the clinical management of osteoporosis. Self-selection bias may have occurred for both physicians who chose to participate and patients who elected to enroll. GI symptoms in the 6 months prior to baseline were patient-reported and may be subject to recall bias. Further, the presence of GI symptoms did not require evidence of medical consultation or treatment; thus, the severity of symptoms cannot be ascertained. Although GI symptoms were associated with lower scores on patient-reported outcomes, we cannot infer causation. Further, although scores in patients with GI symptoms were consistently and significantly lower than patients without GI symptoms, the differences were small and may not be clinically significant. We adjusted scores for multiple patient demographic and clinical characteristics; however, there may have been other unmeasured factors that could have influenced results.

\section{Conclusions}

Our results suggest that GI symptoms may deter patients from complying with therapy and have an adverse effect on treatment satisfaction, quality of life, and use of health care resources. MUSIC-OS will follow treated patients for 1 year and provide a comprehensive assessment of contemporary treatment patterns and patient-reported outcomes in Europe and Canada. Future analyses will explore overall medication discontinuation/switching patterns, patient rationale for discontinuation, adherence, treatment satisfaction, HRQoL, fracture incidence, and health care utilization. The association between treatment-emergent GI symptoms and these outcomes will also be assessed. These results will provide additional insight to improve clinical management of osteoporotic women.

\section{Compliance with ethical standards}

Conflicts of interest This study was funded by Merck \& Co, Inc. A. Modi, S. Sen, A.M. Nguyen, S. Sajjan, and J. P. Weaver are employees of Merck \& Co. and own stock in the company. J. D. Adachi has received grant support and speaker honorarium from Actavis, Amgen, Eli Lilly, Merck \& Co., Inc., and Novartis and is a consultant for Amgen, Eli Lilly, and Merck \& Co., Inc. S. Adami has received consulting honorarium from Merck \& Co., Inc. and serves as a board member for Merck \& Co., Inc. Bernard Cortet has received consulting fees for work as an expert or speaker for Amgen, Ferring, Lilly, Medtronic, Merck, Novartis, Roche Diagnostics, Rottapharm, and Servier and funding for research programs and investigator fees from Amgen, Merck, Novartis, and Servier. A.L. Cooper has received research grants, advisory board, and/ or speaker honorarium from Amgen, Consilient Health, GlaxoSmithKline, Merck Sharp \& Dohme, Novartis, Proctor and Gamble, ProStrakan, Roche, Servier, and Shire. J.P. van den Bergh is a paid consultant at Amgen and Will Pharma and has received research grants and speaker honorarium from Amgen, Will Pharma, and Eli Lilly. P. Geusens and D. Mellström have declared no competing interests.

Medical writing support was provided by Optum (Eden Prairie, MN, USA) and was funded by Merck \& Co., Inc.

Open Access This article is distributed under the terms of the Creative Commons Attribution-NonCommercial 4.0 International License (http:// creativecommons.org/licenses/by-nc/4.0/), which permits any noncommercial use, distribution, and reproduction in any medium, provided you give appropriate credit to the original author(s) and the source, provide a link to the Creative Commons license, and indicate if changes were made.

\section{Appendix}

Table 5

\begin{tabular}{|c|c|c|c|c|c|}
\hline Investigator Name & Site Name & Department & City & State / Province & Country \\
\hline Dr. Jonathan Adachi & & & Hamilton & Ontario & Canada \\
\hline Dr. Aliya Khan & Oakville Bone Centre & & Oakville & Ontario & Canada \\
\hline Dr. Bradley Schweitzer & $\begin{array}{l}\text { The Medical Arts Health } \\
\text { Research Group }\end{array}$ & & Powell River & $\mathrm{BC}$ & Canada \\
\hline Dr. Kevin Saunders & Rivergrove Medical Clinic & & Winnipeg & Manitoba & Canada \\
\hline Dr. Miranda Du Preez & $\begin{array}{l}\text { The Medical Arts Health } \\
\text { Research Group }\end{array}$ & & Kamloops & $\mathrm{BC}$ & Canada \\
\hline Dr. Kenneth Bayly & & & Saskatoon & Saskatchewan & Canada \\
\hline Dr. Tersia Lichtenstein & $\begin{array}{l}\text { The Medical Arts Health } \\
\text { Research Group }\end{array}$ & & Kelowna & $\mathrm{BC}$ & Canada \\
\hline Dr. Richard Boroditsky & Victoria General Hospital & Mature Women's Centre & Winnipeg & Manitoba & Canada \\
\hline Dr. John S. Corey & $\begin{array}{l}\text { The Medical Arts Health } \\
\text { Research Group }\end{array}$ & & West Vancouver & $\mathrm{BC}$ & Canada \\
\hline Dr. Jay Sinha & Steeple Hill Medical Centre & & Pickering & Ontario & Canada \\
\hline Dr. Jack Kooy & $\begin{array}{l}\text { The Medical Arts Health } \\
\text { Research Group }\end{array}$ & & Penticton & $\mathrm{BC}$ & Canada \\
\hline
\end{tabular}


Table 5 (continued)

\begin{tabular}{|c|c|c|c|c|c|}
\hline Investigator Name & Site Name & Department & City & State / Province & Country \\
\hline Dr. Arun Nayar & & & Saskatoon & Saskatchewan & Canada \\
\hline Dr. Suzanne Arndt & Regina Medical Centre & & Regina & Saskatchewan & Canada \\
\hline Dr. Iman Mohamed & The Bone Wellness Centre & & Toronto & Ontario & Canada \\
\hline Dr. Wojciech P. Olszynski & Osteoporosis Centre & & Saskatoon & Saskatchewan & Canada \\
\hline Isabelle Legroux & $\begin{array}{l}\text { Centre Hospitalier Régional } \\
\text { Universitaire de Lille }\end{array}$ & Service de Rhumatologie & Lille & & France \\
\hline $\begin{array}{l}\text { Sandrine Malochet } \\
\text { Guinamand }\end{array}$ & Hôpital Gabriel Montpied & Service de Rhumatologie & Clermont-Ferrand & & France \\
\hline $\begin{array}{l}\text { Marie Christine De } \\
\text { Vernejoul }\end{array}$ & Hopital lariboisière & & Paris & & France \\
\hline Christian Roux & Hôpital Cochin & & Paris & & France \\
\hline Eric Thomas & Lapeyronie hospital & Rheumatology & Montpellier & & France \\
\hline Florence Lévy-Weil & Centre Hospitalier & & Argenteuil & & France \\
\hline Corina Ursu & $\begin{array}{l}\text { Amiens Hospital } \\
\text { Association Predos }\end{array}$ & Service de Rhumatologie & Chu Nord & & France \\
\hline Bernard Cortet & $\begin{array}{l}\text { Centre Hospitalier Régional } \\
\text { Universitaire de Lille }\end{array}$ & Service de Rhumatologie & Lille Cedex & & France \\
\hline Francois Barucq & & & Orthez & & France \\
\hline Olivier Bisch & & & Bischheim & & France \\
\hline Philippe Bouche & & & Bully-Les-Mines & & France \\
\hline Nicolas Breton & & & Beziers & & France \\
\hline François Lacoin & Cabinet Médical du Centre & & Albens & & France \\
\hline Georgios Makridis & & & Obernai & & France \\
\hline Philippe Marmor & & & Strasbourg & & France \\
\hline Marcel Ruetsch & & & Dessenheim & & France \\
\hline Denis Taminau & & & $\begin{array}{l}\text { Rosiers } \\
\text { D'egletons }\end{array}$ & & France \\
\hline Michel Bismuth & & & $\begin{array}{l}\text { Labarthe-Sure- } \\
\text { Leze }\end{array}$ & & France \\
\hline Michel Bourgoin & & & Gemenos & & France \\
\hline Didier Sacareau & & & $\begin{array}{l}\text { Labarthe-Sure- } \\
\text { Leze }\end{array}$ & & France \\
\hline Christian Scellier & & & Vourey & & France \\
\hline Jean-Louis Wurtz & & & Mundolsheim & & France \\
\hline Dr. Stephane Le Mouel & & & HINX & & France \\
\hline Dr. Claude Bortolotti & & & Oignies & & France \\
\hline Dr. Bernard Lauer & & & $\begin{array}{l}\text { Colombey-les- } \\
\text { belles }\end{array}$ & & France \\
\hline Dr. Hervé Amar & & & MARSEILLE & & France \\
\hline Dr. Didier Cadinot & & & BROGLIE & & France \\
\hline Dan Mellström & University of Gothenburg & $\begin{array}{l}\text { Public Health and Community } \\
\text { Medicine }\end{array}$ & Goteborg & & Sweden \\
\hline Karl-Goran Thorngren & Skane University Hospital & Department of Orthopaedics & Lund & & Sweden \\
\hline Kristina Akesson & Skåne University Hospital & $\begin{array}{l}\text { Clinical and Molecular } \\
\text { Osteoporosis Unit }\end{array}$ & Malmo & & Sweden \\
\hline Giorgio Gandolini & & & Castellanza & Varese & Italy \\
\hline Mario Barbagallo & $\begin{array}{l}\text { Cattedra Di Geriatria Via } \\
\text { Del Vespro }\end{array}$ & & Palermo & & Italy \\
\hline Ranuccio Nuti & University of Siena & Internal Medicine & Siena & & Italy \\
\hline Marco Di Monaco & Centro Specializzato & $\begin{array}{l}\text { Malattie Metaboliche } \\
\text { dell'Osso }\end{array}$ & Torino & & Italy \\
\hline Gloria Bonaccorsi & University of Ferrara & $\begin{array}{l}\text { Menopause and Osteoporosis } \\
\text { Center }\end{array}$ & Ferrara & & Italy \\
\hline Sandro Giannini & & & Padova & & Italy \\
\hline Silvano Adami & $\begin{array}{l}\text { Azienda Ospedaliera - } \\
\text { Università di Verona }\end{array}$ & Riabilitazione Reumatologica & Verona & & Italy \\
\hline Antonio Del Puente & & & Napoli & & Italy \\
\hline Salvatore Minisola & & & Rome & & Italy \\
\hline Umberto Tarantino & & & Rome & & Italy \\
\hline Maria Luisa Brandi & & Internal Medicine & Florence & & Italy \\
\hline
\end{tabular}


Table 5 (continued)

\begin{tabular}{|c|c|c|c|c|c|}
\hline Investigator Name & Site Name & Department & City & State / Province & Country \\
\hline Ombretta Di Munno & U.O. Reumatologia & & Pisa & & Italy \\
\hline Giovanni Mario D'Avola & & & Catania & Sicily & Italy \\
\hline Maurizio Caminiti & & & Reggio Calabria & & Italy \\
\hline Bruno Frediani & & & Siena & & Italy \\
\hline Claudio Marcocci & University of Pisa & Department of Endocrinology & Pisa & & Italy \\
\hline Franco Grimaldi & & $\begin{array}{l}\text { Endocrinology and } \\
\text { Metabolism Unit }\end{array}$ & Udine & & Italy \\
\hline Paolo Falaschi & Azienda Ospedaliera Sant'Andrea & UOS di Geriatria & Rome & & Italy \\
\hline Mario Biondi & $\begin{array}{l}\text { Centri osteoporosi e malattie del } \\
\text { metabolismo osse }\end{array}$ & & Forli & & Italy \\
\hline Giulia Letizia Mauro & & & Palermo & & Italy \\
\hline Francesco Paolo Cantatore & $\begin{array}{l}\text { Clinica Reumatologica Università } \\
\text { di Foggia }\end{array}$ & Ospedale Colonnello D'Avanzo & Foggia & & Italy \\
\hline Maurizio Muratore & Ospedale Galateo ASL Lecce & Reumatologia & Lecce & & Italy \\
\hline Dr. den Heijer & VU University Medical Center & $\begin{array}{l}\text { Department of Internal Medicine/ } \\
\text { Endocrinology }\end{array}$ & Amsterdam & & The Netherlands \\
\hline Neveen A.T. Hamdy & Leiden University Medical Center & $\begin{array}{l}\text { Department of Endocrinology \& } \\
\text { Metabolic Diseases }\end{array}$ & Leiden & & The Netherlands \\
\hline H.R. Franke & Medisch Spectrum Twente & VKC 17 Gynaecologie/research & Enschede & & The Netherlands \\
\hline JPW van den Bergh & VieCuri Medical Center & Dept. Internal Medicine & Venlo & & The Netherlands \\
\hline Ton Boermans & & & Losser & & The Netherlands \\
\hline Adriaan Kooy & $\begin{array}{l}\text { Bethesda Diabetes Research } \\
\text { Center }\end{array}$ & & Hoogeveen & Drenthe & The Netherlands \\
\hline Nicolaas K. Valk & & & Beverwijk & Noord Holland & The Netherlands \\
\hline Patrick Eavis & Oldfield Surgery & & Bath & & UK \\
\hline Robert Brownlie & Valleyfield Health Centre & & High Valleyfield & Fife & UK \\
\hline Jon Brunskill & The Pulteney Practice & & Bath & Somerset & UK \\
\hline Michael Gumbley & Westbury Group Practice & White Horse Health Centre & Westbury & Wiltshire & UK \\
\hline Richard Gaunt & Rowden Surgery & & Chippenham & Wiltshire & UK \\
\hline Jennifer Litchfield & Pound Hill Medical Group & & Crawley & West Sussex & UK \\
\hline G D Martin & $\begin{array}{l}\text { Greenwood and Sneinton Family } \\
\text { Medical Centre }\end{array}$ & & Sneinton & Nottingham & UK \\
\hline Boo McConnell & St. James' Surgery & & Bath & & UK \\
\hline Terry McCormack & $\begin{array}{l}\text { Whitby Group Practice, Spring } \\
\text { Vale Medical Centre }\end{array}$ & & Whitby & North Yorkshire & UK \\
\hline Narayanan Annamalai & Albany House Medical Centre & & Wellingborough & Northants & UK \\
\hline Devi Srinivasan & Leicester Terrace Health Care Centre & & Northampton & Northamptonshire & UK \\
\hline Alun Cooper & Bridge Medical Centre & & Crawley & West Sussex & UK \\
\hline Amrit Takhar & Wansford and Kings Cliffe practice & & Cambridgeshire & Cambridgeshire & UK \\
\hline Trevor Gooding & Atherstone Surgery & & Warwickshire & & UK \\
\hline Paul Conn & & & Belfast & & UK \\
\hline Ian Parker & Beehive Surgery & & Bath & Somerset & UK \\
\hline Michael Redmond & Broughshane Medical Practice & & Broughshane & & UK \\
\hline John Calvert & Waterloo Medical Centre & & Blackpool & Lancashire & UK \\
\hline Dr. Cookson & Bradford Road Medical Centre & & Trowbridge & Wiltshire & UK \\
\hline Paul Ainsworth & Sherbourne Medical Centre & & Leamington Spa & Warwickshire & UK \\
\hline Amardeep Heer & Danetre Medical Practice & & Daventry & Northamptonshire & UK \\
\hline Nell Wyatt & The Health Centre & Station Approach & Wiltshire & & UK \\
\hline
\end{tabular}




\section{References}

1. Hernlund E, Svedbom A, Ivergard M, Compston J, Cooper C, Stenmark J, McCloskey EV, Jonsson B, Kanis JA (2013) Osteoporosis in the European Union: medical management, epidemiology and economic burden. A report prepared in collaboration with the International Osteoporosis Foundation (IOF) and the European Federation of Pharmaceutical Industry Associations (EFPIA). Arch Osteoporos 8:136

2. Tarride JE, Hopkins RB, Leslie WD, Morin S, Adachi JD, Papaioannou A, Bessette L, Brown JP, Goeree R (2012) The burden of illness of osteoporosis in Canada. Osteoporos Int 23:25912600

3. Guillemin F, Martinez L, Calvert M et al (2013) Fear of falling, fracture history, and comorbidities are associated with healthrelated quality of life among European and US women with osteoporosis in a large international study. Osteoporos Int 24:3001-3010

4. Sanfelix-Genoves J, Hurtado I, Sanfelix-Gimeno G, Reig-Molla B, Peiro S (2011) Impact of osteoporosis and vertebral fractures on quality-of-life. a population-based study in Valencia, Spain (The FRAVO Study). Health Qual Life Outcomes 9:20

5. Abimanyi-Ochom J, Watts JJ, Borgstrom F et al (2015) Changes in quality of life associated with fragility fractures: Australian arm of the International Cost and Utility Related to Osteoporotic Fractures Study (AusICUROS). Osteoporos Int 26:1781-1790

6. Bliuc D, Nguyen ND, Milch VE, Nguyen TV, Eisman JA, JR Center (2009) Mortality risk associated with low-trauma osteoporotic fracture and subsequent fracture in men and women. JAMA 301:513-521

7. Brozek W, Reichardt B, Kimberger O, Zwerina J, Dimai HP, Kritsch D, Klaushofer K, Zwettler E (2014) Mortality after hip fracture in Austria 2008-2011. Calcif Tissue Int

8. Briesacher BA, Andrade SE, Yood RA, Kahler KH (2007) Consequences of poor compliance with bisphosphonates. Bone 41:882-887

9. Wade SW, Curtis JR, Yu J, White J, Stolshek BS, Merinar C, Balasubramanian A, Kallich JD, Adams JL, Viswanathan HN (2012) Medication adherence and fracture risk among patients on bisphosphonate therapy in a large United States health plan. Bone 50:870-875

10. Rabenda V, Mertens R, Fabri V, Vanoverloop J, Sumkay F, Vannecke C, Deswaef A, Verpooten GA, Reginster JY (2008) Adherence to bisphosphonates therapy and hip fracture risk in osteoporotic women. Osteoporos Int 19:811-818

11. Gallagher AM, Rietbrock S, Olson M, van Staa TP (2008) Fracture outcomes related to persistence and compliance with oral bisphosphonates. J Bone Miner Res 23:1569-1575

12. Lo JC, Pressman AR, Omar MA, Ettinger B (2006) Persistence with weekly alendronate therapy among postmenopausal women. Osteoporos Int 17:922-928

13. Siris ES, Harris ST, Rosen CJ, Barr CE, Arvesen JN, Abbott TA, Silverman S (2006) Adherence to bisphosphonate therapy and fracture rates in osteoporotic women: relationship to vertebral and nonvertebral fractures from 2 US claims databases. Mayo Clin Proc 81:1013-1022

14. Cramer JA, Amonkar MM, Hebborn A, Altman R (2005) Compliance and persistence with bisphosphonate dosing regimens among women with postmenopausal osteoporosis. Curr Med Res Opin 21:1453-1460

15. Halpern R, Becker L, Iqbal SU, Kazis LE, Macarios D, Badamgarav E (2011) The association of adherence to osteoporosis therapies with fracture, all-cause medical costs, and all-cause hospitalizations: a retrospective claims analysis of female health plan enrollees with osteoporosis. J Manag Care Pharm 17:25-39
16. Huybrechts KF, Ishak KJ, Caro JJ (2006) Assessment of compliance with osteoporosis treatment and its consequences in a managed care population. Bone 38:922-928

17. Bauer DC, Black D, Ensrud K, Thompson D, Hochberg M, Nevitt M, Musliner T, Freedholm D (2000) Upper gastrointestinal tract safety profile of alendronate: the fracture intervention trial. Arch Intern Med 160:517-525

18. Taggart H, Bolognese MA, Lindsay R et al (2002) Upper gastrointestinal tract safety of risedronate: a pooled analysis of 9 clinical trials. Mayo Clin Proc 77:262-270

19. Reginster JY, Rabenda V (2006) Patient preference in the management of postmenopausal osteoporosis with bisphosphonates. Clin Interv Aging 1:415-423

20. de Groen PC, Lubbe DF, Hirsch LJ, Daifotis A, Stephenson W, Freedholm D, Pryor-Tillotson S, Seleznick MJ, Pinkas H, Wang KK (1996) Esophagitis associated with the use of alendronate. N Engl J Med 335:1016-1021

21. Lanza FL, Hunt RH, Thomson AB, Provenza JM, Blank MA (2000) Endoscopic comparison of esophageal and gastroduodenal effects of risedronate and alendronate in postmenopausal women. Gastroenterology 119:631-638

22. Hamilton B, McCoy K, Taggart H (2003) Tolerability and compliance with risedronate in clinical practice. Osteoporos Int 14: 259-262

23. Knopp-Sihota JA, Cummings GG, Homik J, Voaklander D (2013) The association between serious upper gastrointestinal bleeding and incident bisphosphonate use: a population-based nested cohort study. BMC Geriatr 13:36

24. Vestergaard P, Schwartz K, Pinholt EM, Rejnmark L, Mosekilde L (2010) Gastric and esophagus events before and during treatment of osteoporosis. Calcif Tissue Int 86:110-115

25. Ettinger J, Pressman A, Schein J, Chan J, Silver P, N C (1998) Alendronate use among 812 women: prevalence, complaints, noncompliance with patient instructions. J Managed Care Pharm 488-492

26. Woo C, Gao G, Wade S, Hochberg MC (2010) Gastrointestinal side effects in postmenopausal women using osteoporosis therapy: 1year findings in the POSSIBLE US study. Curr Med Res Opin 26:1003-1009

27. Yun H, Curtis JR, Guo L et al (2014) Patterns and predictors of osteoporosis medication discontinuation and switching among Medicare beneficiaries. BMC Musculoskelet Disord 15:112

28. Barrett-Connor E, Wade SW, Do TP, Satram-Hoang S, Stewart R, Gao G, Macarios D (2012) Treatment satisfaction and persistence among postmenopausal women on osteoporosis medications: 12month results from POSSIBLE US. Osteoporos Int 23:733-741

29. Modi A, Sen S, Adachi JD, et al. (2015) Rationale and design of MUSIC OS-EU: an international observational study of the treatment of postmenopausal women for osteoporosis in Europe and Canada. Clin Exp Rheumatol 33:in press

30. Breuil V, Cortet B, Cotte FE, Arnould B, Dias-Barbosa C, Gaudin AF, Regnault A, Roborel de Climens A, Legrand E (2012) Validation of the adherence evaluation of osteoporosis treatment (ADEOS) questionnaire for osteoporotic post-menopausal women. Osteoporos Int 23:445-455

31. Flood EM, Beusterien KM, Green H, Shikiar R, Baran RW, Amonkar MM, Cella D (2006) Psychometric evaluation of the Osteoporosis Patient Treatment Satisfaction Questionnaire (OPSAT-Q), a novel measure to assess satisfaction with bisphosphonate treatment in postmenopausal women. Health Qual Life Outcomes 4:42

32. Cheung K, Oemat M, M O, R R (2009) User guide: basic information on how to use EQ-5D

33. Silverman SL (2000) The osteoporosis assessment questionnaire (OPAQ): a reliable and valid disease-targeted measure of health 
related quality of life (HRQoL) in osteoporosis. Qual Life Res 9: 767-774

34. Freemantle N, Cooper C, Roux C et al (2010) Baseline observations from the POSSIBLE EU(R) study: characteristics of postmenopausal women receiving bone loss medications. Arch Osteoporos 5:61-72

35. Penning-van Beest FJ, Goettsch WG, Erkens JA, Herings RM (2006) Determinants of persistence with bisphosphonates: a study in women with postmenopausal osteoporosis. Clin Ther 28:236-242
36. Rossini M, Bianchi G, Di Munno O, Giannini S, Minisola S, Sinigaglia L, Adami S, Treatment of Osteoporosis in clinical Practice Study G (2006) Determinants of adherence to osteoporosis treatment in clinical practice. Osteoporos Int 17:914-921

37. Tosteson AN, Do TP, Wade SW, Anthony MS, Downs RW (2010) Persistence and switching patterns among women with varied osteoporosis medication histories: 12-month results from POSSIBLE US. Osteoporos Int 21:1769-1780 